\title{
STRATEGI STASIUN TV9 LOMBOK DI ERA DISRUPSI
}

\author{
Sahril Halim, Anang Sujoko, Antoni \\ Universitas Brawijaya \\ sahril_halim@student.ub.ac.id, \\ anangsujoko@ub.ac.id, ant kom@ub.ac.id
}

\begin{abstract}
Disruption era is a period that requires television broadcasters to do media innovation and creativity to keep up with the times and technology. The tight competition in the broadcasting industry requires that media companies are able to survive in the face of competitors. This paper aims to analyze the strategies used by TV9 Lombok, so that still exist in the media competition is intense. Innovation and creativity against the content of the news and entertainment media, as well as the application of divergence be a strategy used by TV9 Lombok to stay afloat. The methods used in this research is qualitative interpretive approach to address the strategies implemented by TV9 Lombok. Results of the study that the application of divergence by TV9 Lombok is to respond to changes in the way the audience in watching television broadcasts that were previously conventionally, but now the public can enjoy the content of television broadcasts online. The concept of this divergence is applied as the effort's effectiveness in promoting the TV9 broadcasts by utilizing streaming youtube, social media to web news portals to closer to their audience. So do TV9 Lombok as efforts in maintaining its existence in the world of broadcasting.
\end{abstract}

Keywords: Media strategy, Divergence, TV9 Lombok, Disruption. 


\begin{abstract}
Abstrak
Era disrupsi merupakan suatu periode yang mengharuskan media penyiaran televisi untuk melakukan inovasi dan kreatifitas untuk mengikuti perkembangan zaman dan teknologi. Ketatnya kompetisi dalam industri penyiaran mengharuskan perusahaan media mampu survive dalam menghadapi kompetitor.Paper ini bertujuan untuk menganalisis strategi yang digunakan oleh stasiun TV9 Lombok, sehingga tetap eksis dalam kompetisi media yang sangat ketat. Inovasi dan kreatifitas terhadap konten berita dan hiburan serta penerapan divergensi media menjadi strategi yang digunakan oleh TV9 Lombok agar tetap bertahan. Metode yang digunakan dalam penelitian ini adalah pendekatan kualitatif interpretatif untuk menjawab strategi yang dilaksanakan oleh stasiun TV9 Lombok. Hasil penelitian bahwa penerapan divergensi oleh TV9 Lombok adalah untuk menjawab perubahan cara audiensdalam menonton siaran televisi yang sebelumnya secara konvensional, namun kini publik dapat menikmati konten siaran televisi secara daring. Konsep divergensi ini diterapkan sebagai upaya efektivitas TV9 dalam penyebarluasan siaran dengan memanfaatkan streaming youtube, media sosial hingga web portal berita untuk mendekatkan diri ke hadapan pemirsanya. Hal demikian dilakukan TV9 Lombok sebagai upaya dalam mempertahankan eksistensinya dalam dunia penyiaran.
\end{abstract}

Kata Kunci: Strategi Media, Divergensi, TV9 Lombok, Disrupsi. 


\section{A. Pendahuluan}

Perkembangan

media

penyiaran terus berubah seiring dengan perubahan teknologi yang mengikutinya. Hadirnya internet selama satu dekade terakhir membuat platform media daringtelah mempengaruhi setiap lini kehidupan masyarakat. Hal ini mulai dari cara pertemanan, debat politik, penegakan hukum hingga jurnalisme. Perkembangannya kemudian secara khusus di bidang pertelevisian yang dimulai dari platform seperti Twitter, Facebook, dan Youtube yang telah memberikan pengaruhnya dari praktik sosial dan budaya televisi yang mengikuti pola produksi hingga distribusi penyiaran yang sebelumnya konvensional dan hanya mengandalkan siaran terrestrial. ${ }^{1}$ Hadirnya layanan berbasis online menurut Albarran (2010) dalam Doyle (2014) yang secara dramatis mengubah cara konsumen dalam berkomunikasi dan mengkonsumsi konten media televisi. Tren ini berimbas terhadap pola konsumsi media juga berubah, seperti menerima konten informasi

1 Jose Van Dijck \&Thomas Poell. Making Public Television Social? Public Service Broadcasting and the Challenges of Social Media. (USA: Television \& New Media, Vol. 16(2).2015),2. dengan menggunakan perangkat yang terhubung ke internet. ${ }^{2}$

Penggunaan internet dalam mengonsumsi konten media televisi menyebabkan "disrupsi media". Disrupsi atau gangguan ini terjadi karena perubahan teknologi dan inovasi yang mengikutinya. Istilah disrupsi (Disruption) awalnya diperkenalkan oleh Clayton M. Christensendalam jurnalnya,The Innovator's Dilemma : When New Technologies Cause great Firms to Fail (1997). Disruption berasal dari kata disruptive innovation yang diartikan sebagai gangguan inovasi terhadap inovasi sebelumnya. Pemanfaatan teknologi dan inovasi juga dilakukan oleh perusahaan dalam mempertahankan eksistensinya, namun di sisi lain hadirnya disrupsi inovasi dan teknologi membuka peluang perubahan yang sulit diprediksi sebelumnya oleh perusahaan yang memimpin pasar. ${ }^{3}$

Sejumlah perusahaan yang tergeser oleh perubahan teknologi

2 Gillian Doyle. Media Ownership: Diversity Versus Efficiency in a Changing Technological Environment. Handbook of the Economics of Art and Culture(Elsevier B.V. Vol 2.2014) 359 .

3 Clayton Michael Christensen. The Innovator's Dilemma: When New Technologies Cause great Firms to Fail. (Boston, USA: Harvard Business School. 1997), 34. 
yang digunakan lebih baru dari sebelumnya. Banyak perusahaan terkemuka gagal mempertahankan posisi mereka ketika dihadapkan dengandisrupsi/gangguanteknologi baru, seperti Goodyear dan Firestone terlambat beralih ke penggunaan ban radial, Xerox menyaksikan Canon menciptakan pasar mesin fotokopi dengan ukuran yang minimalis, Bucyrus-Erie membiarkan Caterpillar dan Deere mengambil alih pasar ekskavator. Menurut Bower dan Christensen disrupsi teknologi terhadap perusahaan besar terjadi karena, (1) mereka salah membaca teknologi baru yang digunakan untuk keluar sebagai pemimpin pasar saat itu, dan (2) mereka terlalu memperhatikan pelanggan mereka saat itu, dan tidak berusaha mencari pelanggan baru. ${ }^{4}$ Disruptionera merupakan periode saat inovasi pada masa lalu akan digantikan dengan beragam inovasi baru, yang awalnya dilihat hanya sebatas pengembangan kreatifitas, namunlambatlauninovasi baru ini secara berangsur-angsur menggantikan inovasi lama karena perkembangan teknologi serta

4 Joseph L. Bower\&Clayton M. Christensen. Disruptive Technologies: Catching the Wave.(Harvard:Business Review, 1995), 75. perubahan kebutuhan masyarakat yang dinamis. ${ }^{5}$

Disrupsi/gangguan terhadap inovasi ini akhirnya membuat seluruhbidang usaha/bisnis mengalami perubahan yang cepat, dan digantikan dengan inovasiterkini dalam menyempurnakan inovasi sebelumnya. Inovasi dan teknologi datang secara bersamaan dan saling melengkapi, ketika inovasi baru hadir maka teknologi baru inipun akan mengikuti ataupun sebaliknya. Era disrupsi ini harus dilihat oleh pengelola media penyiaran untuk menyusun langkah strategis agar dapat menyesuaikan dengan perkembangan lingkungan yang terus berubah. ${ }^{6}$ Penggunaan internet dalam mengonsumsi konten media televisi menyebabkan gangguan terhadap media atau "disrupsi media”. Menurut Christensen, Horn, \& Johnson (2011)teori disrupsi/gangguan inovasi adalah bagaimana perusahaan berjuang dengan jenis inovasi tertentu dan

5 Clayton M.C, Michael B. Horn \& Curtis W. Johnson. Disrupting Class: How Disruptive Innovation Will Change the Way the World Learns. (New York and London: Mc Graw Hill, 2011), 12.

6 Rhenald Kasali. Meluruskan Pemahaman soal "Disruption."Dalam Kompas. com. Retrieved from https://ekonomi. kompas.com/read/2017/05/05/073000626/ meluruskan.pemahaman.soal.disruption. 
bagaimana perusahaan bisnis dapat diprediksi berhasil dalam inovasi yang didukung oleh teknologi yang sesuai dengan perkembangan zaman yang dinamis.

Irawan

(2018) menyatakan dengan hadirnya internet maka hampir seluruh industri menghadapi 'musuh-musuh yang tidak kelihatan'. Pelaku bisnis harus menggunakan strategi yang tepat untuk menghadapi kemungkinan gangguan (disrupsi) dari kompetitor baru yang menggunakan teknologi terkini. Beberapa faktor yang mesti dilakukan adalah (1). Selalu memikirkan kepentingan audiens, (2). Mempersiapkan cara untuk mengatasi disrupsi yang mungkin terjadi, (3.) memahami peran budaya, (4). Mengevaluasi sumber daya yang dimiliki, (5). Mengevaluasi pola interaksi menuju efesiensi, (6). Melakukan penetapan prioritas tindakan. Pengelola media penyiaran harus dinamis mencermati setiap perubahan yang terjadi dan terus melakukan inovasi sesuai dengan kebutuhan perusahaan. ${ }^{7}$

Hal inipun terjadi pada perusahaan media tradisional dalam

7 Judith Felecia Pattiwael Irawan. Tantangan Bagi Perguruan Tinggi Dalam Menyongsong Era Digital. (Bandung: Univeristas Katolik Parahyangan, 2018). menghadapi tantangan besar dari media digital terutama dengan hadirnya internet (new media). Hal ini sesuai dengan hasil penelitianYin (2011)yang menyatakan sejak era digital hadir, maka hubungan antara media tradisional dan new media terjadinya pemindahan "waktu dan fungsi". Pengembangan media digital telah membawa kemajuan secara ilmiah dan teknologi serta transformasi signifikan dari struktur sosial, dalam mengembangkan fungsi integrasi produk berita dari media tradisional ke arah media digital. $^{8}$

Disruption Era merupakan satu masa yang harus dihadapi oleh seluruh perusahaan atau bidang usaha yang bergelut dalam bidang apapun. Hal ini disebabkan karena disrupsi (gangguan) inovasi yang terjadi dalam setiap bidang usaha yang dijalankan. Tak terkecuali pada bidang penyiaran yang harus menyusun langkah strategis agar dapat menyesuaikan dengan perkembangan lingkungan yang terus berubah. Disrupsi terhadap pasar media menurut Lugmayr \&

8 Qi Yin. Risk of social disruption and integration function development of news products of traditional media in the digital age. Proceedings of 2011 International Conference on Product Innovation Management (ICPIM, 2011), 70. 
Zotto $(2016)^{9}$ akan menciptakan sejumlah peluangbarukarena adanya evolusi terhadap sejumlah model bisnis media melalui divergensi media. Seperti jalur evolusi model bisnis pada surat kabar, majalah, dan industri media penyiaran dengan memperhatikan sistem kepercayaan terhadap model bisnis baru. Inovasi merupakan salah satu upaya yang harus dilakukan oleh media penyiaran dalam mempertahankan eksistensinya.

Menyikapi era disrupsi ini maka media penyiaran televisi tidak hanya mengandalkan cara yang monoton, seperti yang dikatakan Jenkins $(2006)^{10}$ jika satu perusahaan media dengan divisi/bagian yang berbeda, terusberusaha menerapkan beragam strategi yang dikembangkan. Strategi dalam menyalurkan konten oleh perusahaan media penyiaran menurut Allan (2010) ${ }^{11}$ adalah

9 Artur Lugmayr \& Cinzai dal Zotto How Does Social Media Shape Media Convergence? The Case of Journalists Covering War and Conflict. (Eds.), Media Convergence Handbook Vol. 1: Journalism, Broadcasting, and Social Media Aspects of Convergence (Vol. 1). (New York and London: Springer,2016).

10 Henry Jenkins. Convergence Culture: Where Old and New Media Collide ( New York, USA: New York University Press.2006).

11 Stuart Allan. Media Convergence: In Cultural and Media Studies(New York, USA: Mc Graw, 2010). dengan memanfaatkan berbagai macam bentuk konten yang dipilih, serta menggunakan platform yang disesuaikan dengan pemirsa. Hal ini merupakan bagian dari strategi terpadu dalam mengikuti pola konsumsi pemirsa yang sesuai dengan kebutuhan publik. Strategi yang digunakan media penyiaran dalam menghadapi kompetisi terutama dalam menghadapi era disrupsiadalahdenganmelaksanakan divergensi media.

Selain itu perusahaan media dalam memproduksi konten dipengaruhi oleh struktur perusahaan, strategi, manajemen, dan sumber daya yang dimiliki akan mempengaruhi sifat dan pasokan konten yang diproduksi. ${ }^{12}$ Peran dari organisasi media dan sumber daya yang digunakan dapat dikelola secara efisien, sertamembandingkankinerja organisasi media dalam situasi yang berbeda, sehingga akan diketahui bagaimana industri media mengelola sumber-sumber daya yang terbatas, untuk memproduksi konten yang didistribusikan kepada khalayak sesuai dengan kebutuhan mereka. Setiap proses yang dilakukan oleh mediapenyiaranuntukmenghasilkan

12 Sylvia M. Chan-olmsted \&Byeng-hee Chang. Diversification Strategy of Global Media Conglomerates: Examining Its Patterns and Determinants(USA: Hollifield,2019), 214. 
konten dan mendistribusikannnya kepada audiens sebagai upaya untuk mendapatkan pemasukan berupa iklan merupakan bagian dari aktivitas ekonomi media. ${ }^{13}$

$\begin{array}{ccr}\text { Distribusi } & \text { konten } & \text { dengan } \\ \text { memanfaatkan } & \text { teknologi } & \text { yang }\end{array}$
mendukung alur kerja produksi konten hingga proses penyebarluasan (divergensi) secara multiplatform. Perusahaan media penyiaran memanfaatkan divergensi konten melalui berbagai platform media untuk meningkatkan jumlah pemirsanya atau konsumen. ${ }^{14}$ Divergensi menurut Lugmayr dan Zotto (2016) dikatakan sebagai proses peyebarluasan konten media yang ditandai dengan pengembangan fitur tambahan dan menjadi berbagai bentuk media baru yang muncul dari bentuk awalnya yang serupa ataupun mengalami perubahan bentuk. ${ }^{15}$ Divergensi akan terus mengalami perkembangan secara dinamis sesuai dengan perkembangan teknologi. Senada denganitu, Jenkins dalam Kackman,

13 Allan B. Albarran, Sylvia M. ChanOlmsted \& Michael O. Wirth. Handbook Of Media Management And Economics. (A. B. Albarran, Ed.), Handbook of media management and economics(New Jersey: LE.2006), 566.

14 Seppo Leminen, Juho-petteri Huhtala \& MerviRajahonka. Business Model Convergence and Divergence in Publishing Industries.(USA: Vol 1. 2016), 191.

15 Artur Lugmayr \& Cinzai dal Zotto. How Does Social 403.
Binfield, Payne, Perlman, \& Sebok (2011) ${ }^{16}$ divergensi ditempatkan sebagai suatu diversifikasi saluran media dan mekanisme pengiriman. Sebelumnya Jenkins pernah menegaskan bahwa divergensi memiliki arti sebagai keberagaman saluran media yang dimiliki, kemudian dalam akses pengirimannya menggunakan mekanisme tertentu. ${ }^{17}$

Hasil survery yang dilakukan Nielsen (2017), bahwa adanya peningkatan konsumsi media digital, karena semakin banyak ditemukan konsumen yang menonton televisi dan menggunakan internet dalam waktu yang bersamaan (dual-screen). Peningkatan konsumsi dual-screen yang rutin dilakukan setiap hari dapat ditemukan di semua kelompok usia. Bahkan di kelompok usia 50 tahun ke atas, mereka yang melakukan dualscreen setiap hari pun meningkat dari 7\% di tahun 2015 menjadi 48\% di tahun 2017. Dari survey ditemukan bahwa saat ini ada beragam cara yang dilakukan untuk mengakses konten TV atau film. TV terrestrial dan TV kabel masih menjadi pilihan utama dengan perolehan 77 persen, namun akses konten video melalui platform digital juga cukup tinggi

16 Kackman, dkk.. Flow TV: Television in the age of media convergence. Flow TV: Television in the Age of Media Convergence(New York, USA: Routledge Taylor \& Francis Group, 2011), 57. 17 Henry Jenkins. Convergence Culture.... 
seperti misalnya situs streaming seperti Youtube, Vimeo dsb (51\%), portal TV online (44\%), TV internet berlangganan seperti Netflix, Iflix, Hooq, dan lain sebagainya mencapai $28 \%{ }^{18}$

Pemanfaatan media digital bagi pengelola media penyiaran dilakukan sebagai salah satu strategi dalam menyebarluaskan konten (divergensi) melalui layanan daring. Hal ini pun terjadi pada media penyiaran lokal di provinsi Nusa Tenggara Barat, salah satunya adalah media penyiaran TV9 Lombok. Produksi konten berita dan hiburan media TV9 Lombok awalnya disiarkan secara analog sesuai dengan coverage area melalui kanal 60 UHF. Namun kini tidak hanya mengandalkan siaran terrestrial akan tetapi menerapkan proses divergensi media dengan merambah ke arah multiplatform berbasis internet, yaitu dengan memanfaatkan streaming youtube, media sosial, hingga portal website TV9 lombok dalam menyebarluaskan kontennya.

18 RO-Micom.SurveiNielsen:Masyarakat Indonesia Makin Gemar Internetan.. Retrieved from http://mediaindonesia.com/read/ detail / 114722-survei-nielsen-masyarakatindonesia-makin-gemar-internetan (Rabu, 26 Jul 2017, 17:23 WIB)
TV9 Lombok sebagai media penyiaran di daerah harus lebih kreatif dan inovatif dalam menghadapi disrupsi media. Maka untuk menjawab tantangan disrupsi tersebut TV9 Lombok menerapkan divergensi untuk dapat menjawab permasalahan publik yang tidak hanyamenonton siarantelevisisecara konvensional, namun audiens dapat menikmati konten siaran televisi secara daring. Dengan menggunakan divergensi media merupakan strategi yang dijalankan media penyiaran dalam menyebar luaskan sekaligus mendistribusikan ulang konten siaran secara menyeluruh.

\section{B. Model Penelitian}

Penelitian ini menggunakan pendekatan kualitatif untuk mempelajari hal-hal yang sesuai dengan keadaan alaminya kemudian mencoba untuk memahami, menafsirkan, fenomena dalam arti makna yang melingkupi orang-orang dan sekitarnya. ${ }^{19}$ Fokus penelitian menurut Moleong (2015) berfungsi sebagai pedoman dalam melakukan pembahasanterhadaphasilpenelitian

19 Norman K. Denzin, \& Yvonna S. Lincoln. The SAGE Handbook of Qualitative Research. The SAGE Handbook(London: SAGE Publications Ltd, 2005). 
yang telah ditetapkan. ${ }^{20}$ Penelitian ini berusaha untuk fokus terhadap proses produksi konten berita yang dilakukan oleh divisi pemberitaan dalam penyebarluasan (divergensi) konten berita dan hiburanmelalui media konvensional (analog) ataupun media digital (streaming). Pengumpulan data yaitu dengan cara pengumpulan data primer dan wawancara terhadap sumber data yang dipilih secara purposive sampling atau penentuan sampel secara langsung. Neuman (2014) menjelaskan purposive adalah tipe sampel yang berharga untuk situasi khusus yang digunakan dalam penelitian eksplorasi untuk mengidentifikasi kasus tertentu berdasarkan kriteria tertentu, karena tujuannya adalah untuk menemukan sebanyak mungkin kasus untuk mendapatkan pemahaman yang lebih mendalam. ${ }^{21}$

Penentuan informan dipilih berdasarkan kriteria memiliki pengalaman di bidang media penyiaran, tanggung jawab yang diemban lebih dari satu bidang dan

20 Lexy J.Moleong. Metode Penelitian Kualitatif (Bandung: Remaja Rosda Karya,2015).

21 Lawrence W. Neuman. Social Research Methods: Qualitative and Quantitative Approaches(London: PearsonNew International Edtion2014). berkaitan dengan divisi lainnya, jabatan yang strategis dalam menjalankan media penyiaran serta pengetahuan mereka yang luas dan mendalam terhadap media penyiaran tv9 Lombok. Setelah pengumpulan data telah dilakukan, selanjutnya diklasifikasikan untuk dianalisis melalui tiga sub proses yang saling berkaitan. Analisis data menurut Miles, Huberman \& Saldana (2014) melalui tiga proses, yaitu (1) Condensation Data (Kondensasi), (2) Data display atau Penyajian data, dan (3) Conclusion: drawing/verification atau penarikan kesimpulan/verifikasi. ${ }^{22}$

\section{TV9 Lombok di Era Disrupsi}

Dalam menghadapi era disrupsi mengharuskan mediapenyiaran TV9 Lombok melihat peluang sekaligus menghadapi tantangan terutama dari kompetitor media lainnya. Pemanfaatan konvergensi media telah dilaksankan sebagai bentuk efektivitas produksi konten. Hal ini berkaitan erat dengan penggunaan berbagai macam perangkat dalam memproduksi konten pemberitaan. Produksi program acara yang dilaksanakan oleh media televisi

22 Matthew B.Miles, Michael A. Huberman \& Johny Saldana. Qualitative Data Analysis A Methods Sourcebook(United States Of America: SAGE Publications, Inc, 2014). 
merupakan bagian dari siklus sebuah industri. Hal ini sesuai dengan penjelasan Grindstaff \& Turow (2006), bahwa industri televisi yang melibatkan banyak faktor termasuk dalam proses distribusi dan pemrograman yang sangat kompleks, karena membutuhkan beragam aspek yang melibatkan unsur pembuatan program siaran seperti budaya perusahaan, keahlian teknis dan pemasaran dalam mendistribusikan konten sebagai sebuah produkyangdipancarluaskan kepada masyarakat. ${ }^{23}$

Program acara berita dikemas dalam news bulletin Lintas 9, yang berada di bawah divisi pemberitaan dan produksi. Divisi ini harus bekerjasama dengan divisi teknis dalam menyiarkan konten yang dihasilkan dan dapat dinikmati oleh seluruh pemirsa melalui layar kaca TV9. Hal ini Dimulai dari peran seorang produser, kameraman, reporter, news anchor/presenter, grafis, master control room (MCR) yang memiliki peran yang samasama penting demi kelancaran produksikonten hingga proses siaran dilaksanakan. Hal ini sesuai dengan

23 Laura Grindstaff\&Joseph Turow. Video Cultures: Television Sociology in the "New TV" Age. Annual Review of Sociology, 32(1), 2006, 103-125.
Lawson (2003) yang menyatakan bahwa dibutuhkan kerjasama bagi para editor, manajer, reporter, photographer/cameraman dalam situasi kerja dalam tingkah laku yang kooperatif dalam berbagi konten berita dan ide. ${ }^{24}$

Manajer Pemberitaan dan Produksi, Yana Febriana Chandra menyatakan bahwa acara yang diproduksi dalambentuknewsbulletin oleh news room adalah Lintas 9 pagi dimulai pada pukul 09.30-10.30 Wita, Lintas 9 siang dimulai pada pukul 13.00-14.00 Wita, dan untuk Lintas 9 sore dimulai pada pukul 17.00-18.00 Wita. Dalam memproduksi acara Lintas 9, setiap pengelola memiliki tanggung jawab yang berbeda-beda namun saling berkaitan antara satu dengan yang lainnya. karena setiap personel saling melengkapi dan membutuhkan, seperti tugas seorang Video Jurnalis (VJ) yang bertugas meliput materi berita di lapangan, mulai dari merekam gambar, menulis naskah/narasi, dubbing, mengedit bahan berita hingga siap ditayangkan.

24 Gracie Lawson-Borders. Integrating new media and old media: Seven observations of convergence as a strategy for best practices in media organizations, International Journal on Media Management, No 5, Vol 2, 2003. 95. 
VJ membutuhkan bantuan dari tim MCR (master control room) untuk menyiarkan paket berita yang siap untuk ditayangkan. Begitupula dengan tugas dari seorang reporter yang membutuhkan kameraman dan editor dalam membuat sebuah kemasan program acara yang siap untuk ditayangkan. Proses komunikasi dan kerjasama yang berjalan ini sesuai dengan penjelasan Lawson(2003)bahwakerjasamayang mengkaitkan staf dari departemen/ divisi yang berbeda dan unit bisnis untuk melakukan kolaborasi dalam mengembangkan dan mengeksekusi ide dari sebuah konten. ${ }^{25}$

Proses penyiaran konten berita dan hiburan memperhatikan kebutuhan masyarakat yang menjadi isu hangat di sekitar lingkungan mereka hingga kegemaran masyarakat yang berkembang. Menurut Yana Chandra jika porsi konten pemberitaan sekitar $40 \%$ dan konten hiburan sebesar $60 \%$ untuk memberikan nuansa hiburan yang mendidik (edutainment) kepada masyarakat. Penyiaran konten berita dan hiburan awalnya dilakukan secara konvensional, namun dengan perkembangan teknologi saat ini membuat stasiun TV9 tidak hanya mengandalkan siaran analog melalui

25 Ibid. kanal 60 UHF. Daya jangkau siaran yang masih terbatas, sehingga TV9 menggunakan kanal youtube/ streaming dalam menyebarluaskan konten siarannya.

Usman hadi selaku manajer teknik menjelaskan, sejakakhir tahun 2017 pihaknya telah menggunakan kanal youtube/streamingTV9, dalam menyebarluaskan konten siaran. Hal ini sesuai dengan pendapat Fuchs (2008) yang menilai bahwa media perlu memanfaatkan beragam platform dalam memberikan informasi kepada publik, yaitu tentang informasi yang dibutuhkan oleh institusi terkait. Hal ini sebagai strategi untuk mendapatkan perhatian pemirsa dalam menggunakan perangkat yang tersedia sebagai upaya alternatif dalam berkomunikasi. Pemanfaatan kanal youtube dimaksudkan agar masyarakat dapat mengakses konten siaran kapan saja dan dimanapun, sehingga akan terlihat secara real time berapa jumlah viewer (penonton) ataupun yang berlangganan (subscribe) terhadap saluran youtube TV9.

Divergensi (penyebarluasan) konten mediadengan memanfaatkan saluran youtube akan membuat pemirsa televisi memiliki banyak pilihan dalam menggunakan media 
yang sesuai dengan kebutuhan masayarakat. Konten siaran berita yang bersumber dari media TV9 akan dinikmati secara menyeluruh dan lebih luas. Sesuai dengan analisa Hendricks (2010), divergensi ini dapat meningkatkan jumlah pemirsa, namun disisi lainnya perhatian penonton akan terbagi dengan banyaknya pilihan dan loyalitas pemirsa terhadap satu atau dua stasiun televisi akan terus berubah. Hal ini mengharuskan manajer televisi lokal untuk mengevaluasi konten siarannya sehingga mampu memenangkan kompetisi dengan media TV lainnya. ${ }^{26}$

Minardi selaku konsultan media penyiaran tv9 Lombok, menjelaskan bahwa telah menerapkan beragam strategi dalam mengikuti perubahan zaman yang dinamis, terutama bagi media penyiaran yang tidak boleh ketinggalan dalam memanfaatkan media terbaru dalam upaya menarik keinginan audiens, sehingga dibutuhkan kreatifitas dan inovasi dalam setiap aktivitas penyiaran yang dilaksanakan. Dengan perubahan zaman dan perkembangan teknologi

26 John Allen Hendricks. The Twenty-FirstCentury Media Industry Economic and Managerial Implications in the Age of New Media (United Kingdom: Lexington Books, 2010). digital yang semakin memudahkan proses penyiaran sehingga media penyiaran tv9 mengembangkan kreatifitas dan inovasi dalam menjawab perubahan di era disrupsi media. Pola pengembangan kreatifitas yang dilaksanakan dalam menghadapi disrupsi media adalah peningkatan jam siar yang sebelumnya hanya sembilan jam setiap haridan kini telah bersiaran selama 14 jam setiap harinya.

Seiring dengan perkembangannya dalam memenuhi kebutuhan masyarakat terhadap informasi dan hiburan, maka pada tanggal 5 juni 2017 penambahan jam siar menjadi 14 jam, yaitu dimulai pada pukul 08.00 hingga 22.00 WITA. Penambahan durasi siaran menurut Minardi yaitu dengan memperhatikan biaya operasional dan ketersediaan sumber daya manusia (SDM) yang dibutuhkan oleh media tv9 dalam menjalankan roda penyiaran dengan baik dan bertanggung jawab. Berikut Tabel perkembangan jam siaran media penyiaran tv9 Lombok.

Tabel 1. Perkembangan Jam Siar Media Penyiaran TV9 Lombok

\begin{tabular}{|c|c|c|c|}
\hline No. & Tahun & $\begin{array}{c}\text { Jam Siar } \\
\text { (WITA) }\end{array}$ & Ket. \\
\hline 1. & $\begin{array}{c}10 \text { Oktober } \\
2010\end{array}$ & $\begin{array}{c}16.00- \\
18.00\end{array}$ & 2 Jam \\
\hline 2. & $\begin{array}{c}24 \text { Oktober } \\
2010\end{array}$ & $\begin{array}{c}16.00- \\
20.00\end{array}$ & 4 Jam \\
\hline
\end{tabular}




\begin{tabular}{|c|c|c|c|}
\hline 3. & $\begin{array}{c}9 \text { Februari } \\
2011\end{array}$ & $\begin{array}{c}16.00- \\
21.00\end{array}$ & 5 Jam \\
\hline 4. & 1 April 2011 & $\begin{array}{c}15.00- \\
22.00\end{array}$ & 7 Jam \\
\hline 5. & 1 Juli 2011 & $\begin{array}{c}14.00- \\
23.00\end{array}$ & 9 Jam \\
\hline 6. & $\begin{array}{c}\text { 6 Januari } \\
2014\end{array}$ & $13.00-22.00$ & 9 Jam \\
\hline 7. & $\begin{array}{c}\text { 5 Juni } 2017- \\
\text { Sekarang }\end{array}$ & $\begin{array}{c}08.00- \\
22.00\end{array}$ & 14 Jam \\
\hline
\end{tabular}

Sumber : Diolah Peneliti

Dijelaskan Minardi, peningkatan jam siar yang dilaksanakan merupakan strategi untuk dapat meningkatkan posisi tawar di tengah masyarakat dan kepada pihak pengiklan. penambahan jam siar secara bertahap, merupakan upaya untuk lebih memperkuat eksistensi media penyiaran di tengah ketatnya kompetisi media penyiaran di daerah. Selain itu, dengan durasi siaran yang lebih tinggi (lama) akan memudahkan media penyiaran dalam memasarkan produk berupa konten berita/hiburan kepada calon klien (pengiklan) sesuai dengan kebutuhan dari pengguna jasa media penyiaran.

Selain itu menurutnya dibutuhkan pengembangan inovasi dan kreatifitas terhadap konten berita dan hiburan untuk menjangkau audiens yang tidak dicover oleh siaran terestrial. Hal ini disiasati dengan pemanfaatan divergensi media dengan menggunakan multiplatform, seperti penggunaan youtube streaming, media sosial (facebook dan instagram) hingga web portal pemberitaan, yang penyajiannya berupa gambar dan teks berita melalui layanan daring. Berikut gambar alur divergensi media dalam menyiarkan konten siaran tv9 Lombok.

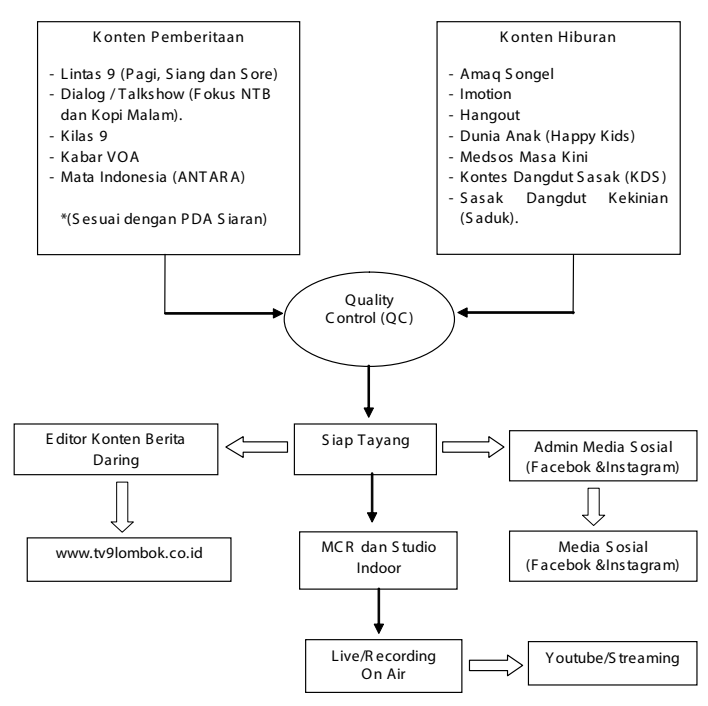

Gambar 2. Alur pemanfaatan divergensi media TV9 Lombok

Dengan strategi yang tepat dan keputusan manajemen akan dapat menstabilkan posisi media di antara penonton yang memiliki pilihan yang beragam. Hadirnya layanan berbasis online seperti yang dikatakan Albarran (2010) ; Doyle(2014), secara dramatis mengubah cara konsumen dalam berkomunikasi dan mengonsumsi konten media televisi. Tren ini berimbas terhadap pola konsumsi media berubah, seperti menerima konten informasi dengan menggunakan perangkat 
yang terhubung ke internet melalui beragam platform. ${ }^{27}$

Penanggung jawab information \& technology (IT),I wayan putrayasa yang berada di bawah divisi teknis menjelaskan tentang penggunaan beragam media untuk menyampaikan pesan kepada masyarakat. Selain streaming youtube, digunakan pula websitetv9. lombok.co.id, media sosial seperti facebook dan instagram dimanfaatkan untuk mengupdate setiap materi siaran yang akan ditayangkan. Dari laman media sosial inipun TV9 akan mendapatkan respon dari masyarakat berupa komentar, saran dan kritik yang nantinya akan langsung mendapatkan feedback dari admin tv9 yang digunakan sebagai bahan acuan dalam peningkatan kualitas siaran.

Penerapan divergensi media yang dilakukan oleh media penyiaran tv9 sesuai dengan penjelasan seorang analis teknologi James Lewin, yaitu divergensi merupakan distribusi media televisi yang mengalami perubahan bentuk sehingga media mainstream harus mengenali dan memanfaatkan media YouTube,

27 Gillian Doyle,Media Ownership: Diversity Versus Efficiency, (2014). podcast video dan media lainnya. ${ }^{28}$ Selain itu penggunaan media sosial seperti facebook dan instagram yang digemari oleh seluruh lapisan masyarakat, merupakan bagian dari strategi media TV9 untuk semakin medekatkan dirinya kepada pemirsa. Hal ini seperti yang dijelaskan Dominick (2005), ${ }^{29}$ bahwa strategi dalam mempertahankan eksistensi media TV adalah memperluas saluran distribusi siaran dengan menggunakan seluruh jaringan yang ada, serta melalui promosi (on air) ataupun pameran (off air) untuk mengenalkan seluruh konten siaran yang dimiliki oleh media TV9 Lombok.

\section{Penutup}

Menyikapi era disrupsi, media penyiaran televisi tidak hanya mengandalkan cara yang monoton, jika satu perusahaan media dengan divisi yang berbeda berusaha menerapkan beragam strategi yang dikembangkan. Aktivitas ekonomi media terlihat dari penggunaan sumber daya dan produksi konten

28 Brooke E. Duffy, Tara Liss-Mariño \& Katherine Sender,Reflexivity in Television Depictions of Media Industries: Peeking Behind the Gilt Curtain, (USA: Culture \& Critique,2011).

29 Joseph R. Dominick, The Dynamics of Mass Communications, (New York, USA: Mc Graw Hill, 2005). 
hingga proses distribusi konten yang dilakukan. Penyaluran konten media penyiarandengan memanfaatkan berbagai macam bentuk konten yang dipilih, serta menggunakan platform yang disesuaikan dengan pemirsa. Era disrupi mengharuskan media penyiaran TV9 Lombok jeli melihat peluang sekaligus menghadapi tantangan terutama dari kompetitor media lainnya. Jawaban dari tantangan disrupsi yang yang dihadapi TV9 Lombok adalah menerapkan divergensi media. Tidak hanya itu, dalam mengembangkan kreatifitas dan inovasi dalam penyiaran konten yang lebih luas dengan meningkatkan jam siar hingga 14 jam sehari. Hal ini menjadi problem solvingterhadap kebutuhan audiens, sehingga TV9 tidak hanya menghadirkan siaran televisi secara konvensional namun juga secara daring.

Divergensi media merupakan fungsi yang dibutuhkan dalam menyebar luaskan sekaligus mendistribusikan ulang konten siaran secara menyeluruh. Konsep divergensi ini diterapkan sebagai upaya efektivitas TV9 dalam memproduksi konten pemberitaan dan hiburan, dan penyebarluasan siaran dengan memanfaatkan streaming dan media sosial untuk mendekatkan diri ke hadapan pemirsanya. Hal demikian dilakukan TV9 sebagai strategi dalam mempertahankan eksistensinya dalam dunia penyiaran terutama di era disrupsi.Stasiun media TV9 kedepannya harus terus berusaha mengembangkan kreatifitas dan inovasi dalam kompetisi yang semakin ketat dan dinamis. Penelitian ini masih memiliki keterbatasan karena hanya melihat strategi yang diterapkanpadasatumediapenyiaran televisi di daerah Lombok-NTB, sehingga perlu adanya penelitian lanjutan di daerah lainnya karena memiliki kekhasannya tersendiri yang unik dan berbeda,terutama dalam pengelolaan media penyiaran di tiap daerah lainnya. 


\section{Daftar Pustaka}

Jose Van Dijck \& Thomas Poell, Making Public Television Social? Public Service Broadcastingand the Challenges of Social Media,(USA: Television \& New Media, 2015)

Gillian Doyle,Media Ownership: Diversity Versus Efficiency in a Changing Technological Environment, Handbook of the Economics of Art and Culture (Elsevier B.V, 2014)

Clayton Michael Christensen,The Innovator's Dilemma: When New Technologies Cause great Firms to Fail,(Boston, USA: Harvard Business School, 1997)

Joseph L. Bower \& Clayton M. Christensen, Disruptive Technologies: Catching the Wave. (Harvard:Business Review, 1995)

Clayton M.C, Michael B. Horn \& Curtis W. Johnson,Disrupting Class: How Disruptive Innovation Will Change the Way the World Learns, (New York and London: Mc Graw Hill, 2011)

Rhenald Pemahaman Kasali,Meluruskan "Disruption."Dalam Kompas. com. Retrieved fromhttps:// ekonomi.kompas.com/ $\mathrm{read} / 2017 / 05 / 05 / 073000626 /$ meluruskan.pemahaman.soal. disruption.

Judith Felecia Pattiwael Irawan, Tantangan Bagi Perguruan Tinggi Dalam Menyongsong Era Digital,(Bandung: Univeristas Katolik Parahyangan, 2018)

Qi Yin, Risk of social disruption and integration function development of news products of traditional media in the digital age. Proceedings of 2011 International Conference on Product Innovation Management (ICPIM, 2011)

Artur Lugmayr \& Cinzai dal Zotto How Does Social Media Shape Media Convergence? The Case of Journalists Covering War and Conflict. (Eds.), Media Convergence Handbook Vol. 1: Journalism, Broadcasting, and Social Media Aspects of Convergence (Vol. 1). (New York and London: Springer, 2016)

Henry Jenkins. Convergence Culture: Where Old and New Media Collide ( New York, USA: New York University Press, 2006)

Stuart Allan,Media Convergence: In Cultural and Media Studies,(New York, USA: Mc Graw, 2010)

Sylvia M. Chan-olmsted \& Byeng-hee Chang. Diversification Strategy 
of Global Media Conglomerates : Examining Its Patterns and Determinants (USA: Hollifield, 2019)

Allan B. Albarran, Sylvia M. Chan-Olmsted \& Michael O. Wirth,Handbook of Media Management And Economics, (A. B. Albarran, Ed.), Handbook of media management and economics,(New Jersey: LE. 2006)

SeppoLeminen,Juho-petteriHuhtala \& Mervi Rajahonka. Business Model Convergence,(USA: Divergence in Publishing Industries. Vol 1. 2016)

Kackman, dkk.. Flow TV: Television in the age of media convergence. Flow TV: Television in the Age of Media Convergence(New York, USA: Routledge Taylor \& Francis Group, 2011).

RO-Micom. Survei Nielsen: Masyarakat Indonesia Makin Gemar Internetan, Retrieved from http://mediaindonesia. $\mathrm{com} / \mathrm{read} / \mathrm{detail} / 114722$ survei-nielsen-masyarakatindonesia-makin-gemarinternetan (Rabu, 26 Jul 2017, 17:23 WIB)

Norman K. Denzin, \& Yvonna S. Lincoln, The SAGE Handbook of
Qualitative Research. The SAGE Handbook(London: SAGE

Publications Ltd, 2005)

Lexy J.Moleong,Metode Penelitian Kualitatif, (Bandung: Remaja Rosda Karya, 2015).

Lawrence W. Neuman,Social Research Methods:

Qualitative and Quantitative Approaches(London: Pearson New International Edtion2014) Matthew B. Miles, Michael A,Huberman \& Johny Saldana, Qualitative Data Analysis A Methods Sourcebook(United States of America: SAGE Publications, Inc, 2014)

Laura Grindstaff \& Joseph Turow, Video Cultures: Television Sociology in the "New TV" Age,(Annual Review of Sociology, 32, 1, 2006)

Gracie Lawson-Borders, Integrating new media and old media: Seven observations of convergence as a strategy for best practices in media organizations, (International Journal on Media Management, No 5, Vol 2, 2003)

John Allen Hendricks, The TwentyFirst-Century Media Industry Economic and Managerial Implications in the Age of New 
Media, (United Kingdom: Curtain. Communication,(USA: Lexington Books, 2010) Culture \& Critique, 2011)

Brooke E. Duffy, Tara Liss-Mariño Joseph R. Dominick, The Dynamics \& Katherine Sender,Reflexivity of Mass Communications, (New in Television Depictions of Media York, USA: Mc Graw Hill, Industries: Peeking Behind the Gilt 2005) 